\title{
Article \\ The Antifungal Mechanism of Isoxanthohumol from Humulus lupulus Linn.
}

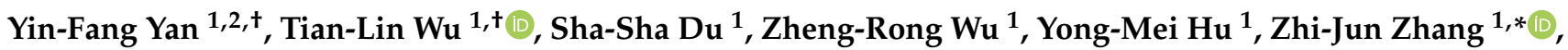 \\ Wen-Bin Zhao ${ }^{1}$, Cheng-Jie Yang ${ }^{1}$ and Ying-Qian Liu ${ }^{1,2, *}$ \\ 1 School of Pharmacy, Lanzhou University, Lanzhou 730000, China; yanyf18@lzu.edu.cn (Y.-F.Y.); \\ wut119@lzu.edu.cn (T.-L.W.); dushsh19@lzu.edu.cn (S.-S.D.); wuzhengrong@lzu.edu.cn (Z.-R.W.); \\ huym20@lzu.edu.cn (Y.-M.H.); zhaowb19@lzu.edu.cn (W.-B.Z.); yangchj16@lzu.edu.cn (C.-J.Y.) \\ 2 State Key Laboratory of Grassland Agro-ecosystems, Lanzhou University, Lanzhou 730000, China \\ * Correspondence: zhangzhijun198803@163.com (Z.-J.Z.); yqliu@lzu.edu.cn (Y.-Q.L.) \\ + These authors contributed equally to this work.
}

check for updates

Citation: Yan, Y.-F.; Wu, T.-L.; Du, S.-S.; Wu, Z.-R.; Hu, Y.-M.; Zhang, Z.-J.; Zhao, W.-B.; Yang, C.-J.; Liu, Y.-Q. The Antifungal Mechanism of Isoxanthohumol from Humulus lupulus Linn. Int. J. Mol. Sci. 2021, 22, 10853. https://doi.org/10.3390/ ijms221910853

Academic Editors: Dejan Stojković, Marija Ivanov and Ana Ćirić

Received: 31 August 2021 Accepted: 27 September 2021 Published: 7 October 2021

Publisher's Note: MDPI stays neutral with regard to jurisdictional claims in published maps and institutional affiliations.

Copyright: (c) 2021 by the authors. Licensee MDPI, Basel, Switzerland. This article is an open access article distributed under the terms and conditions of the Creative Commons Attribution (CC BY) license (https:// creativecommons.org/licenses/by/ $4.0 /)$.

\begin{abstract}
Humulus lupulus Linn. is a traditional medicinal and edible plant with several biological properties. The aims of this work were: (1) to evaluate the in vitro antifungal activity of H. lupulus ethanolic extract; (2) to study the in vitro and in vivo antifungal activity of isoxanthohumol, an isoprene flavonoid from H. lupulus, against Botrytis cinerea; and (3) to explore the antifungal mechanism of isoxanthohumol on B. cinerea. The present data revealed that the ethanolic extract of H. lupulus exhibited moderate antifungal activity against the five tested phytopathogenic fungi in vitro, and isoxanthohumol showed highly significant antifungal activity against $B$. cinerea, with an $\mathrm{EC}_{50}$ value of $4.32 \mu \mathrm{g} / \mathrm{mL}$. Meanwhile, it exhibited moderate to excellent protective and curative efficacies in vivo. The results of morphologic observation, RNA-seq, and physiological indicators revealed that the antifungal mechanism of isoxanthohumol is mainly related to metabolism; it affected the carbohydrate metabolic process, destroyed the tricarboxylic acid (TCA) cycle, and hindered the generation of ATP by inhibiting respiration. Further studies indicated that isoxanthohumol caused membrane lipid peroxidation, thus accelerating the death of $B$. cinerea. This study demonstrates that isoxanthohumol can be used as a potential botanical fungicide for the management of phytopathogenic fungi.
\end{abstract}

Keywords: Humulus lupulus Linn.; isoxanthohumol; antifungal activity; Botrytis cinerea

\section{Introduction}

Over decades, diseases and damages caused by phytopathogenic fungi can greatly diminish the yield and quality of crops [1]. It is estimated that the losses caused by phytopathogenic fungi total more than $\$ 200$ billion each year, which is significantly higher than the losses caused by any other group of microorganisms [2]. Although chemical fungicides are still widely used to reduce plant diseases in agriculture, the abuse of these chemicals has led to toxic residues and resistance among plant pathogenic fungi, which has caused several environmental and health problems [3,4]. Given these major drawbacks and the fact that the public are increasingly sensitive to the use of all chemical fungicides, demand for novel, effective, and environmentally acceptable fungicides has been soaring rapidly [5].

In recent years, natural products have been considered an important and promising source for the research and development of new drugs due to their easy biodegradation and low residual toxicity [6]. Many natural products have been reported to be effective against phytopathogenic fungi [7]. For example, tephroapollin-F, a prenylated flavonoid isolated from Tephrosia apollinea L., effectively inhibited the growth of Colletotrichum acutatum [8]. Pinostrobin and flavokawin B are bioactive compounds from Polygonum stelligerum that have been demonstrated to effectively suppress the growth of Monilinia fructicola and Rhizopus stolonifer [9]. Furthermore, antidesmone, isolated from Waltheria indica, displayed 
broad-spectrum antifungal activities against all tested phytopathogenic fungi with $\mathrm{EC}_{50}$ values ranging from 0.60 to $20.15 \mu \mathrm{g} / \mathrm{mL}$ [1].

Humulus lupulus Linn. (Cannabaceae) is a traditional medicinal and edible plant, commonly named hops, that is widely distributed all over the world [10]. Because of the bitterness and the antiseptic and aromatic properties of its metabolites, it is particularly popular with brewers [11]. However, H. lupulus was originally used for medicinal purposes [12], and it has been demonstrated to display a variety of pharmacological properties, such as antioxidant, estrogenic, antimicrobial, and anti-inflammatory proprieties [13]. H. lupulus contains various terpenes, phytoestrogens, tannins, essential oils, and flavonoids, with abundant activity in vitro. There are many reports about the biological activities of flavonoids in H. lupulus. Mizobuchi reported that xanthohumol and 6-isopentenylnaringenin can effectively inhibit the growth of Staphylococcus aureus, with an MIC value of $6.25 \mu \mathrm{g} / \mathrm{mL}$, while that of isoxanthohumol is $50.0 \mu \mathrm{g} / \mathrm{mL}$ [14]. Bocquet et al. demonstrated that desmethylxanthohumol in H. lupulus showed effective antifungal activity against Zymoseptoria tritici with an MIC value of $0.63 \mathrm{~g} / \mathrm{L}$ [15]. At the same time, Agnieszka et al. also found that xanthohumol can effectively inhibit the growth of three Fusarium species, with $\mathrm{MIC}_{50}$ values ranging from 0.015 to $0.100 \mathrm{mg} / \mathrm{mL}$ [16]. To the best of our knowledge, isoxanthohumol found in H. lupulus has not been reported for potential antifungal activities against phytopathogenic fungi.

Thus, the present study aimed to quantify the content of isoxanthohumol (Figure 1) in H. lupulus and assess its in vitro and in vivo antifungal activity. Then, SEM and TEM were used to observe the effects of isoxanthohumol on B. cinerea, and transcriptomics technology was used to explore the antifungal mechanism of isoxanthohumol against B. cinerea. Finally, RT-qPCR and physiological indicators, such as total carbohydrate content, dehydrogenase activities, cell respiration, adenosine triphosphate (ATP) content, and ATPase activity, were used to validate the results of RNA-seq. Furthermore, we evaluated the effects of isoxanthohumol on $B$. cinerea by observing the changes in cell membrane permeability; the contents of glycerol, MDA, and $\mathrm{H}_{2} \mathrm{O}_{2}$; and antioxidant-related enzyme activity, which provide a theoretical basis for the development of isoxanthohumol.<smiles>COc1cc(O)c(CC=C(C)C)c2c1C(=O)CC(c1ccc(O)cc1)O2</smiles>

Figure 1. The structure of isoxanthohumol.

\section{Results and Discussion}

\subsection{Antifungal Activity of $\mathrm{H}$. lupulus Extract and Its Isoxanthohumol Content}

In this study, ethanolic extract of H. lupulus and isoxanthohumol were prepared firstly. Subsequently, their antifungal activity was determined in vitro. As shown in Table 1, ethanolic extract of $H$. lupulus exhibited moderate antifungal activity against all five pathogenic fungi (inhibition rate: $37.01 \sim 51.52 \%$ at $500 \mu \mathrm{g} / \mathrm{mL}$ ). At the same time, isoxanthohumol, the main isoprene flavonoid from $\mathrm{H}$. lupulus, showed more excellent antifungal activity against pathogenic fungi, especially $B$. cinerea. Then, the content of isoxanthohumol in H. lupulus was analyzed by HPLC, and the results showed that the content of isoxanthohumol is low $(0.052 \mathrm{mg} / \mathrm{g})$ (Figure 2). 
Table 1. Antifungal activity of ethanolic extract from H. lupulus and isoxanthohumol in vitro.

\begin{tabular}{ccccccc}
\hline \multirow{2}{*}{ Compound } & \multirow{2}{*}{$\begin{array}{c}\text { Concentration } \\
(\mu \mathbf{g} / \mathbf{m L})\end{array}$} & $\boldsymbol{R . ~ s o l a n i}$ & B. cinerea & F. graminearum & S. sclerotiorum & M. oryzae \\
\cline { 3 - 6 } & 500 & $37.01 \pm 0.43$ & $44.42 \pm 0.27$ & $48.19 \pm 0.54$ & $51.52 \pm 0.53$ & $43.40 \pm 0.23$ \\
\multirow{2}{*}{ Ethanolic extract } & 250 & $25.66 \pm 0.18$ & $40.76 \pm 0.17$ & $39.56 \pm 0.18$ & $47.97 \pm 0.47$ & $29.34 \pm 0.29$ \\
& 50 & $31.90 \pm 1.08$ & $85.90 \pm 0.24$ & $63.88 \pm 0.23$ & $84.46 \pm 0.30$ & $33.50 \pm 0.27$ \\
Isoxanthohumol & 25 & $18.02 \pm 0.31$ & $78.45 \pm 0.32$ & $60.43 \pm 0.82$ & $79.49 \pm 0.05$ & $28.10 \pm 0.22$ \\
\hline
\end{tabular}

${ }^{\text {a }}$ Each treatment repeated three times. Data are displayed as mean $\pm \mathrm{SD}$.
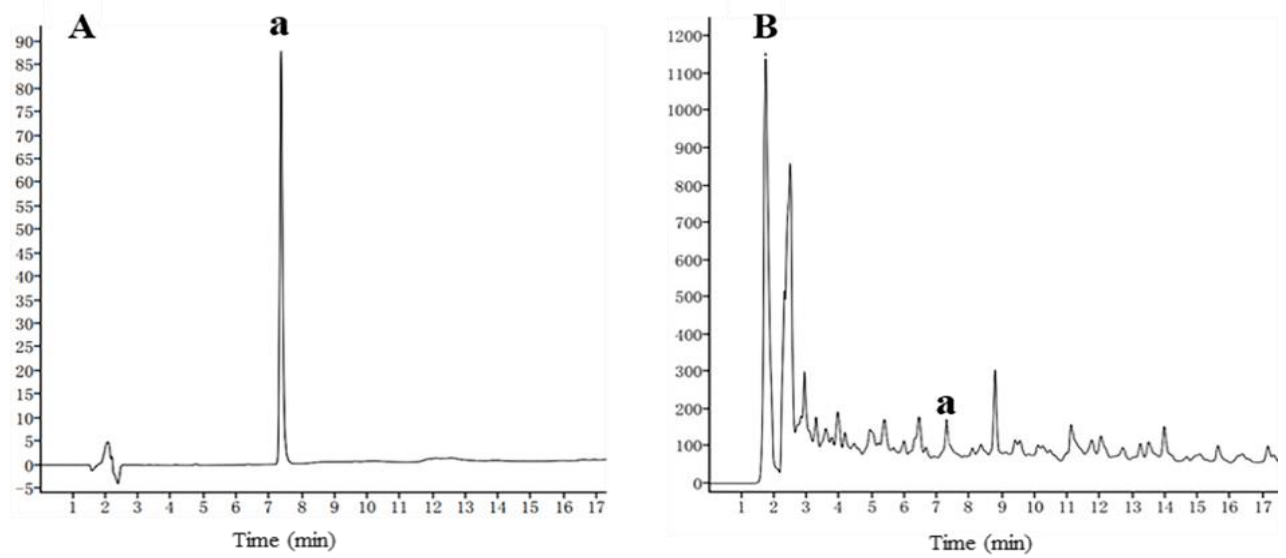

Figure 2. HPLC chromatograms of standards (A) and raw material (B); a: isoxanthohumol.

\subsection{Antifungal Activity of Isoxanthohumol}

The antifungal activity of isoxanthohumol against three common pathogenic fungi in vitro is shown in Table 2: it was effective against $S$. sclerotiorum, B. cinerea, and F. graminearum with $\mathrm{EC}_{50}$ values of $14.52,4.32$, and $16.50 \mu \mathrm{g} / \mathrm{mL}$, respectively. The inhibition rates at 50, $25,10,5$, and $2.5 \mu \mathrm{g} / \mathrm{mL}$ are shown in Table S1. B. cinerea is a ubiquitous pathogenic fungus that can infect a wide range of commercial crops and cause important economic losses [17]. The mechanism of isoxanthohumol on $B$. cinerea remains largely unclear, so it is important to determine the mechanism of action of isoxanthohumol against $B$. cinerea.

Table 2. Inhibition of the mycelia of three plant pathogenic fungi by isoxanthohumol.

\begin{tabular}{cccc}
\hline Pathogenic Fungus & $\mathbf{E C}_{\mathbf{5 0}}(\boldsymbol{\mu g} / \mathbf{m L})$ & Pathogenic Fungus $(\mathbf{y}=\mathbf{a x}+\mathbf{b})$ & $\begin{array}{c}\text { Correlation } \\
\text { Coefficient }\left(\mathbf{R}^{\mathbf{2}}\right)\end{array}$ \\
\hline S. sclerotiorum & 14.52 & $\mathrm{y}=3.78 \mathrm{x}-4.43$ & 0.973 \\
B. cinerea & 4.32 & $\mathrm{y}=2.08 \mathrm{x}-1.38$ & 0.836 \\
F. graminearum & 16.50 & $\mathrm{y}=1.64 \mathrm{x}-2.00$ & 0.976 \\
\hline
\end{tabular}

The investigation into the in vivo antifungal activity showed that isoxanthohumol was effective at inhibiting the growth of $B$. cinerea in isolated cherry tomatoes. As we can see from Table 3 and Figure 3, B. cinerea infection caused serious tissue rot in the blank control. After treatment with $50 \mu \mathrm{g} / \mathrm{mL}, 100 \mu \mathrm{g} / \mathrm{mL}$, and $200 \mu \mathrm{g} / \mathrm{mL}$ of isoxanthohumol for 5 days, the control efficacies were $27.39 \%, 35.23 \%$, and $39.25 \%$, respectively, in terms of curative effect. The protective efficacies of isoxanthohumol and boscalid (positive control) were $32.35 \%, 38.32 \%, 54.85 \%$ and $42.93 \%, 49.09 \%, 69.95 \%$, respectively, at $50 \mu \mathrm{g} / \mathrm{mL}$, $100 \mu \mathrm{g} / \mathrm{mL}$, and $200 \mu \mathrm{g} / \mathrm{mL}$. This study demonstrated moderate to excellent protective and curative effects of isoxanthohumol in vivo. Moreover, isoxanthohumol is the main isoprene flavonoid from the medicinal and edible plant $H$. lupulus [18], so it has the potential to be developed as a botanical fungicide to prevent plant diseases caused by B. cinerea. 
Table 3. The antifungal activity of isoxanthohumol and boscalid in vivo.

\begin{tabular}{|c|c|c|c|c|c|}
\hline \multirow[b]{2}{*}{ Compound } & \multirow{2}{*}{$\begin{array}{l}\text { Concentration } \\
(\mu \mathrm{g} / \mathrm{mL})\end{array}$} & \multicolumn{2}{|c|}{ Protective Effect } & \multicolumn{2}{|c|}{ Curative Effect } \\
\hline & & $\begin{array}{l}\text { Lesion Length }{ }^{a} \\
\quad(\mathrm{~mm} \pm \mathrm{SD})\end{array}$ & Control Efficacy (\%) & $\begin{array}{l}\text { Lesion Length } \\
(\mathrm{mm} \pm \mathrm{SD})\end{array}$ & Control Efficacy (\%) \\
\hline \multirow{3}{*}{ Isoxanthohumol } & 50 & $23.07 \pm 2.62$ & 32.35 & $24.77 \pm 1.23$ & 27.39 \\
\hline & 100 & $21.04 \pm 3.98$ & 38.32 & $22.09 \pm 0.78$ & 35.23 \\
\hline & 200 & $15.40 \pm 2.96$ & 54.84 & $20.72 \pm 1.92$ & 39.25 \\
\hline \multirow{3}{*}{ Boscalid } & 50 & $15.16 \pm 5.02$ & 42.93 & $30.78 \pm 2.52$ & 9.77 \\
\hline & 100 & $13.53 \pm 5.62$ & 49.09 & $16.90 \pm 3.11$ & 50.47 \\
\hline & 200 & $7.98 \pm 2.40$ & 69.95 & $16.71 \pm 3.18$ & 51.00 \\
\hline Control & - & $26.57 \pm 5.04$ & - & $34.11 \pm 2.32$ & - \\
\hline
\end{tabular}

${ }^{a}$ Each treatment repeated five times.

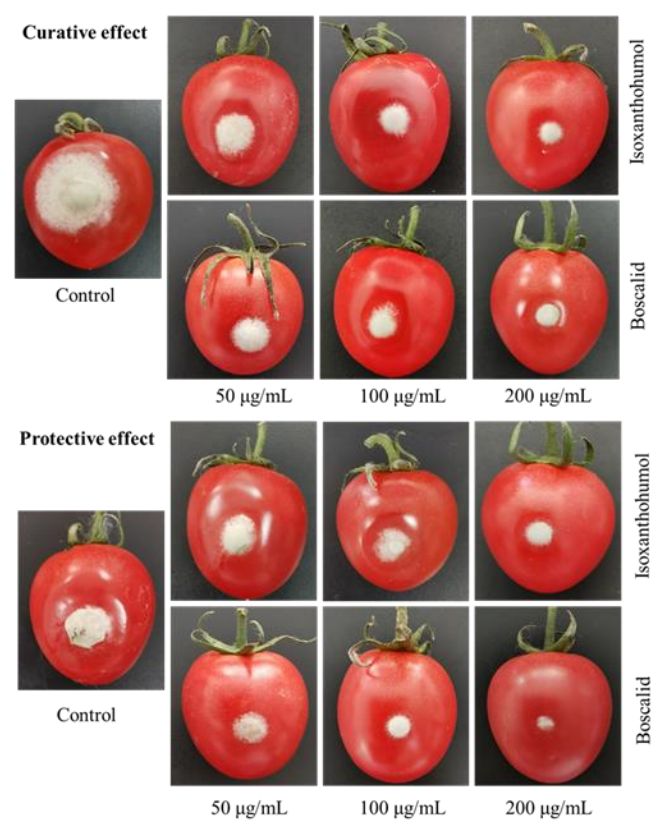

Figure 3. The antifungal activity of isoxanthohumol and boscalid in vivo.

\subsection{Effect of Isoxanthohumol on B. cinerea Spore Germination}

Spores are known as the main source of infection for gray mold; once the environmental conditions are suitable, they germinate to infect the host plant [19]. The effect of isoxanthohumol on B. cinerea spore germination is shown in Figure 4. Most of the spores germinated in the blank control when cultured for $8 \mathrm{~h}$, but the inhibition rate of spore germination reached $100 \%$ when treated with $25 \mu \mathrm{g} / \mathrm{mL}$ of isoxanthohumol. In conclusion, the spore germination of $B$. cinerea was inhibited in a dose-dependent manner.

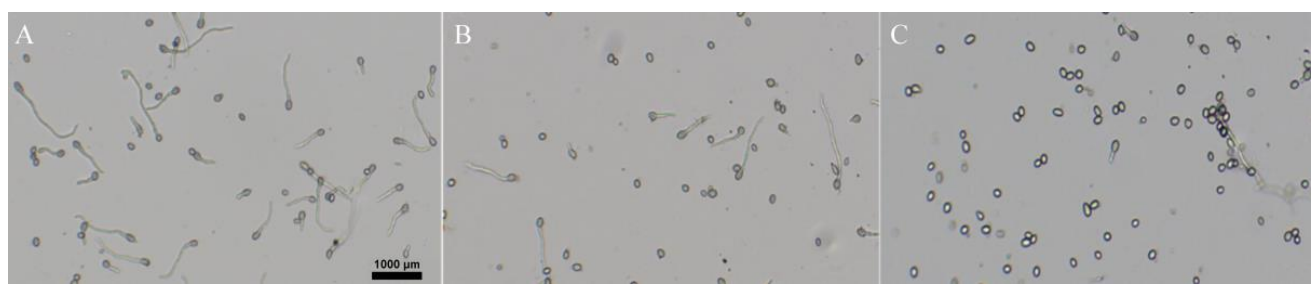

Figure 4. Inhibitory activity of isoxanthohumol on spore germination of B. cinerea: (A) Blank control, (B) $10 \mu \mathrm{g} / \mathrm{mL}$, (C) $25 \mu \mathrm{g} / \mathrm{mL}$. 


\subsection{Effect of Isoxanthohumol on B. cinerea Morphology}

To examine the effect of isoxanthohumol on the morphology and ultrastructure of B. cinerea, SEM and TEM techniques were used. SEM analysis showed that isoxanthohumol caused considerable morphological alterations in B. cinerea. The mycelia in the blank control showed a uniform intact, homogenous, and robust morphology, and they exhibited smooth surfaces. By contrast, mycelia were deformed, bent, and collapsed after treatment with isoxanthohumol (Figure 5). The results of TEM observation indicated that isoxanthohumol could lead to significant alteration and disorganization of the cell ultrastructure. Compared to the blank control sample, B. cinerea under $5 \mu \mathrm{g} / \mathrm{mL}$ of isoxanthohumol displayed an abnormal cell ultrastructure, which caused lysis; the plasma membrane was thickened and damaged; mitochondria had slightly swollen; and plasmolysis was obvious. Some organelles, such as the liposome and nucleus, disappeared (Figure 6). All of these results demonstrated that isoxanthohumol caused significant damage to the morphology and ultrastructure of B. cinerea.
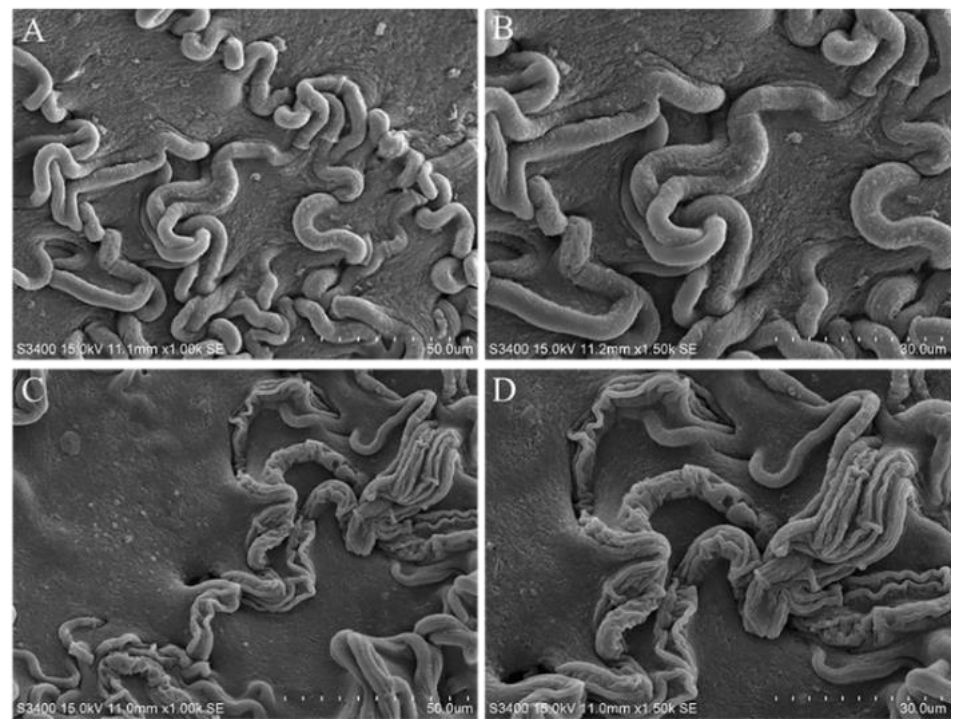

Figure 5. Scanning electron microscopy observations of the morphology of $B$. cinerea mycelia: (A) Blank control, 0.5\% DMSO, $\times 10$; (B) Blank control, 0.5\% DMSO, $\times 1500$; (C) Treated with 0.5\% DMSO plus isoxanthohumol at $5 \mu \mathrm{g} / \mathrm{mL}, \times 10$; (D) Treated with $0.5 \%$ DMSO plus isoxanthohumol at $5 \mu \mathrm{g} / \mathrm{mL}, \times 1500$.

\subsection{Transcriptome Analysis of B. cinerea under Isoxanthohumol Treatment}

To better understand the molecular changes underlying the impact of isoxanthohumol on $B$. cinerea, a transcriptome profiling assay was performed on the two samples-a blank control and treatment (5 $\mu \mathrm{g} / \mathrm{mL}$ of isoxanthohumol). Transcriptome analysis of the effects of isoxanthohumol on B. cinerea is showen in Figure 7. As illustrated in the volcano plot (Figure 7A), 3944 significantly differentially expressed genes (DEGs) were screened, among which 2088 DEGs were significantly upregulated and 1856 were downregulated in the treatment group when compared with the blank control ( $\mid \log _{2}$ (Fold Change) $\mid \geq 2$ and $q$ value $\leq 0.001$ ). Subsequently, the significantly differentially expressed genes (DEGs) were compared with the Gene Ontology (GO) database, and the DEGs were found to be mainly involved in three types of processes: biological process, cellular component, and molecular function (Figure 7B). Next, 334 DEGs related to the metabolic process in the biological process were chosen to execute GO enrichment analysis and Kyoto Encyclopedia of Genes and Genomes (KEGG) enrichment analysis, and the results indicated the expression of 109 DEGs involved in the carbon metabolism pathway and another 27 DEGs involved in the TCA cycle pathway (Figure 7C). Further analysis demonstrated that these DEGs mainly focus on the ATP metabolic process, generation of precursor metabolites 
and energy, and purine ribonucleotide metabolic process, especially energy metabolism, carbohydrate metabolism, cell growth, and amino acid metabolism. Key enzyme genes associated with the TCA cycle, including citrate synthase, succinate dehydrogenase, and other dehydrogenases, were also differentially expressed. Therefore, we speculate that isoxanthohumol may cause significant damage to the whole metabolic pathway, including carbon metabolism, the TCA cycle, ATP generation, and respiration. Based on this speculation, we evaluated the effects of isoxanthohumol on the total carbohydrate content, dehydrogenase activities, CA content, ATP content, ATPase activity, and cell respiration to validate the results of transcriptomics.
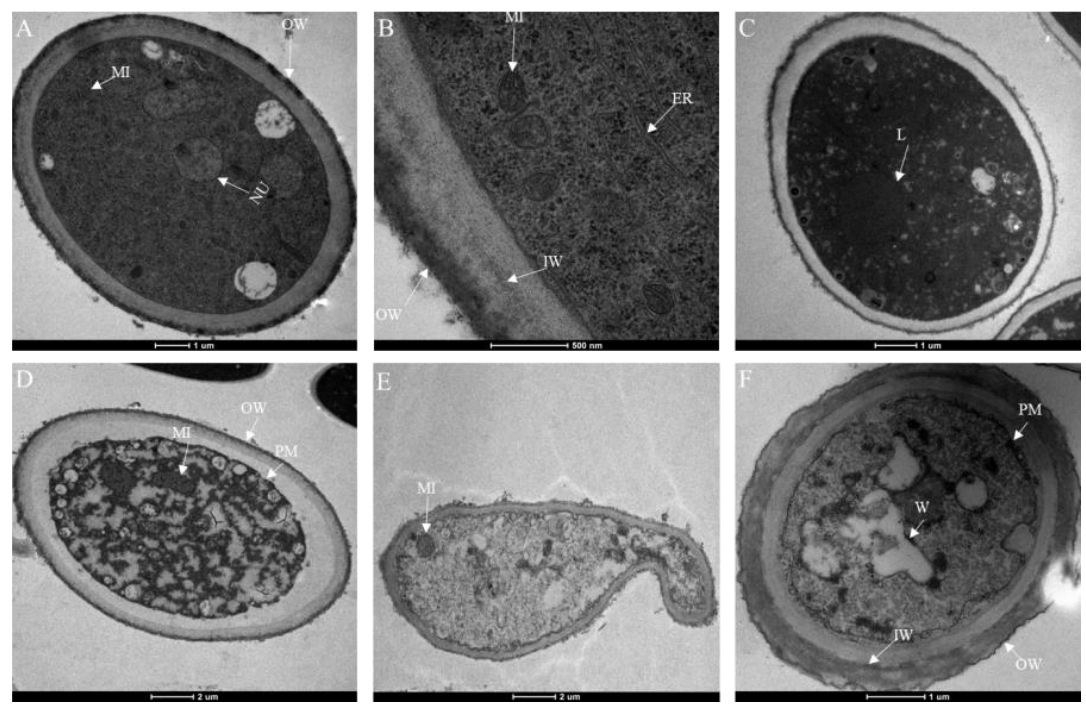

Figure 6. Transmission electron micrographs of the B. cinerea cell structure: $(\mathbf{A}-\mathrm{C})$ Blank control, $0.5 \%$ DMSO; (D-F) Treated with 0.5\% DMSO plus isoxanthohumol at $5 \mu \mathrm{g} / \mathrm{mL}$; OW: outer wall; IW: inner wall; MI: mitochondria; NU: nucleus; ER: endoplasmic reticulum; L: lipid body; PM: plasma membrane.
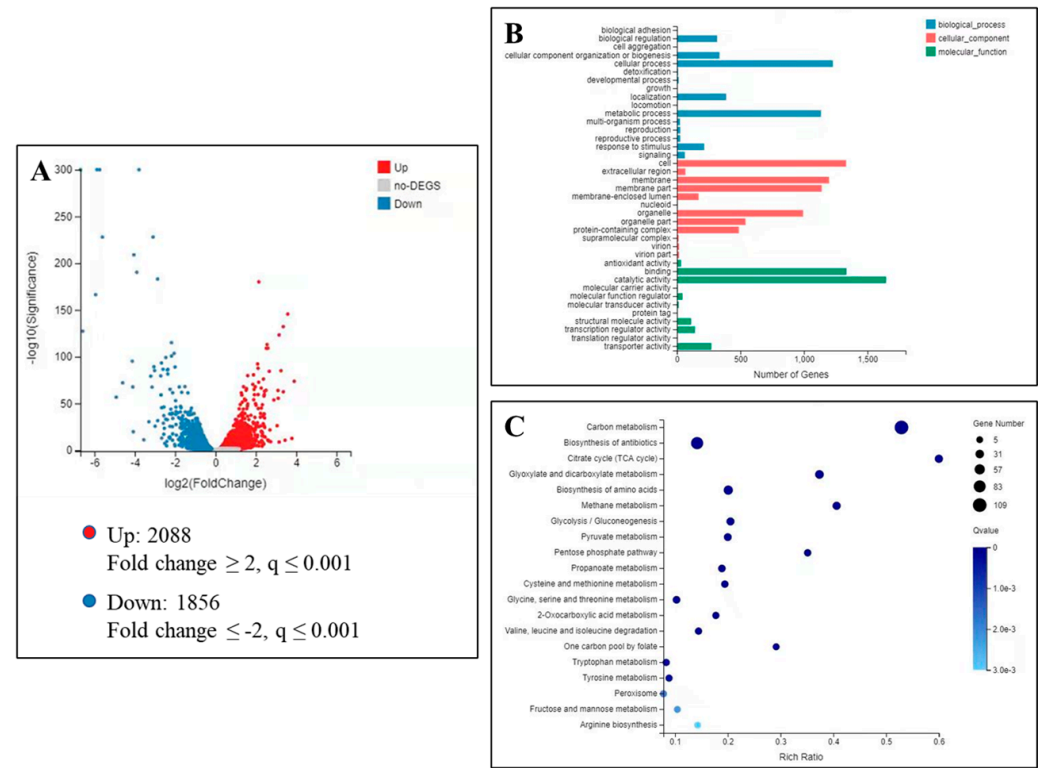

Figure 7. Transcriptome analysis of the effects of isoxanthohumol on B. cinerea. (A) A volcano plot of the DEGs from control/isoxanthohumol (the $X$-axis represents value A ( $\log _{2}$-transformed mean expression level), the $Y$-axis represents value $M$ ( $\log _{2}$-transformed fold change)); (B) DEG numbers of the most enriched GO terms; (C) KEGG enrichment analysis of DEGs. 


\subsection{Verification of DEGs by RT-qPCR}

To validate the expression of the DEGs identified in the transcriptome results for the $B$. cinerea mycelia, seven genes (six upregulated genes and one downregulated gene) were randomly selected from the results for RT-qPCR analysis. Within the seven selected genes, five genes were related to carbon metabolism and two genes were related to the TCA cycle. It can be seen in Figure 8 that all the changes in the chosen genes tested in RT-qPCR were consistent with the results of the RNA-Seq, and some genes were found to be most significantly different in the blank control and treatment, which confirmed that the RNA-seq data were reliable.
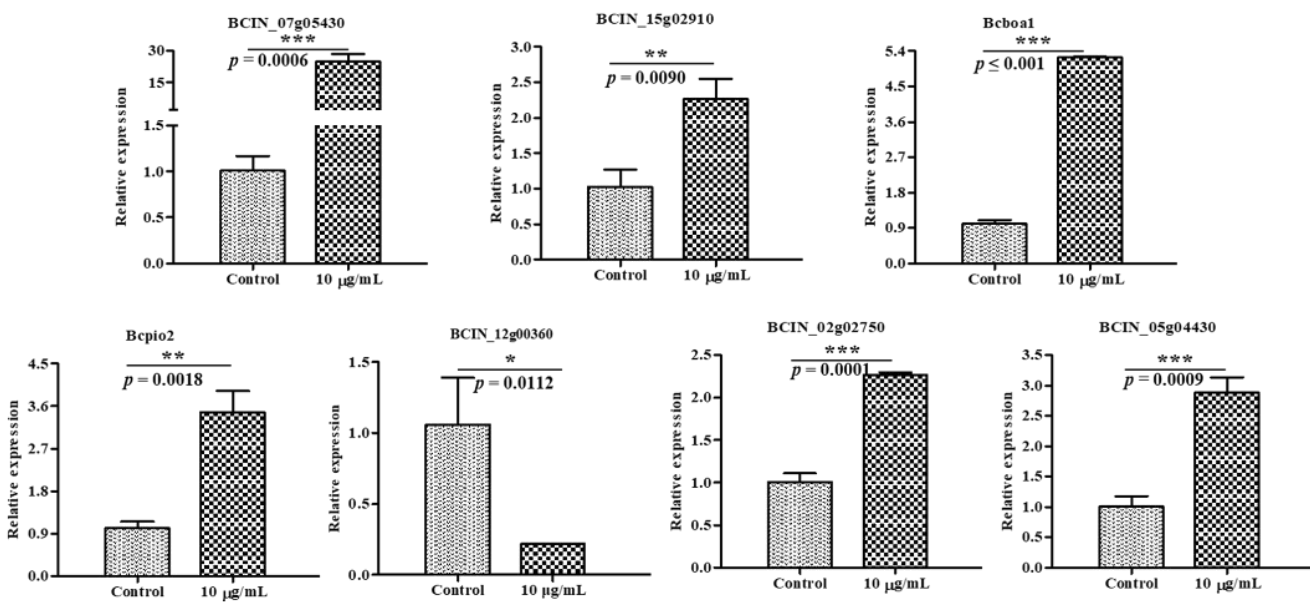

Figure 8. Verification of DEGs by RT-qPCR. ${ }^{*} p<0.05,{ }^{* *} p<0.01$ and ${ }^{* * *} p<0.001$.

\subsection{Effects of Isoxanthohumol on B. cinerea Total Carbohydrate Content and TCA Cycle}

The DEGs involved in the carbohydrate metabolic process were found to be most significantly different among the transcriptome results. Carbohydrates are the main carbon sources in the TCA cycle, and inhibition of them would cause damage to the metabolic pathways. Carbohydrate metabolism is one of the main metabolic pathways and forms of energy supply in fungi, including biochemical pathways for biosynthesis, degradation, interconversion, and energy metabolism [20,21]. Effect of isoxanthohumol on the mycelial metabolism was evaluated (Figure 9). Figure 9A shows that isoxanthohumol decreased the total carbohydrate content of $B$. cinerea in a concentration-dependent manner. After treatment with $5.0 \mu \mathrm{g} / \mathrm{mL}$ and $10.0 \mu \mathrm{g} / \mathrm{mL}$ of isoxanthohumol, the total carbohydrate content was decreased by $18.23 \%$ and $22.41 \%$, respectively. This indicated that the carbohydrate metabolic capability of B. cinerea was seriously impaired by isoxanthohumol.

The DEGs involved in the TCA cycle were also noticed by their amount and the significance of the transcriptome results. Carbohydrates are the main carbon sources in the TCA cycle, and inhibition of them would cause damage to the TCA cycle [22]. MDH plays an important role in the energy-producing pathway and catalyzes the interconversion of malate to oxaloacetate, while SDH catalyzes the oxidation of succinate to fumarate in the TCA cycle [23]. The activities of key enzymes related to the TCA cycle are shown in Figure 9B. Compared with the blank control, the SDH and MDH enzyme activities demonstrated most significant decreases $(p<0.001)$ in $B$. cinerea cells as the concentration of isoxanthohumol increased. The MDH activities were decreased by $52.36 \%$ and $93.19 \%$ at $5.0 \mu \mathrm{g} / \mathrm{mL}$ and $10.0 \mu \mathrm{g} / \mathrm{mL}$ of isoxanthohumol, respectively, and the SDH activities were decreased by $47.50 \%$ and $92.50 \%$, respectively, at the same concentrations. Intracellular citrate functions as a key regulator of energy metabolism, modulates ATP production, and is the prime carbon source for fatty acid synthesis in the cytoplasm [24]. The CA content in B. cinerea was also inhibited by isoxanthohumol at concentrations of 5.0 and $10.0 \mu \mathrm{g} / \mathrm{mL}$, decreasing by $17.78 \%$ and $62.39 \%$, respectively, compared with the blank control. This 
demonstrated that isoxanthohumol may inhibit the growth of B. cinerea by affecting the TCA cycle.
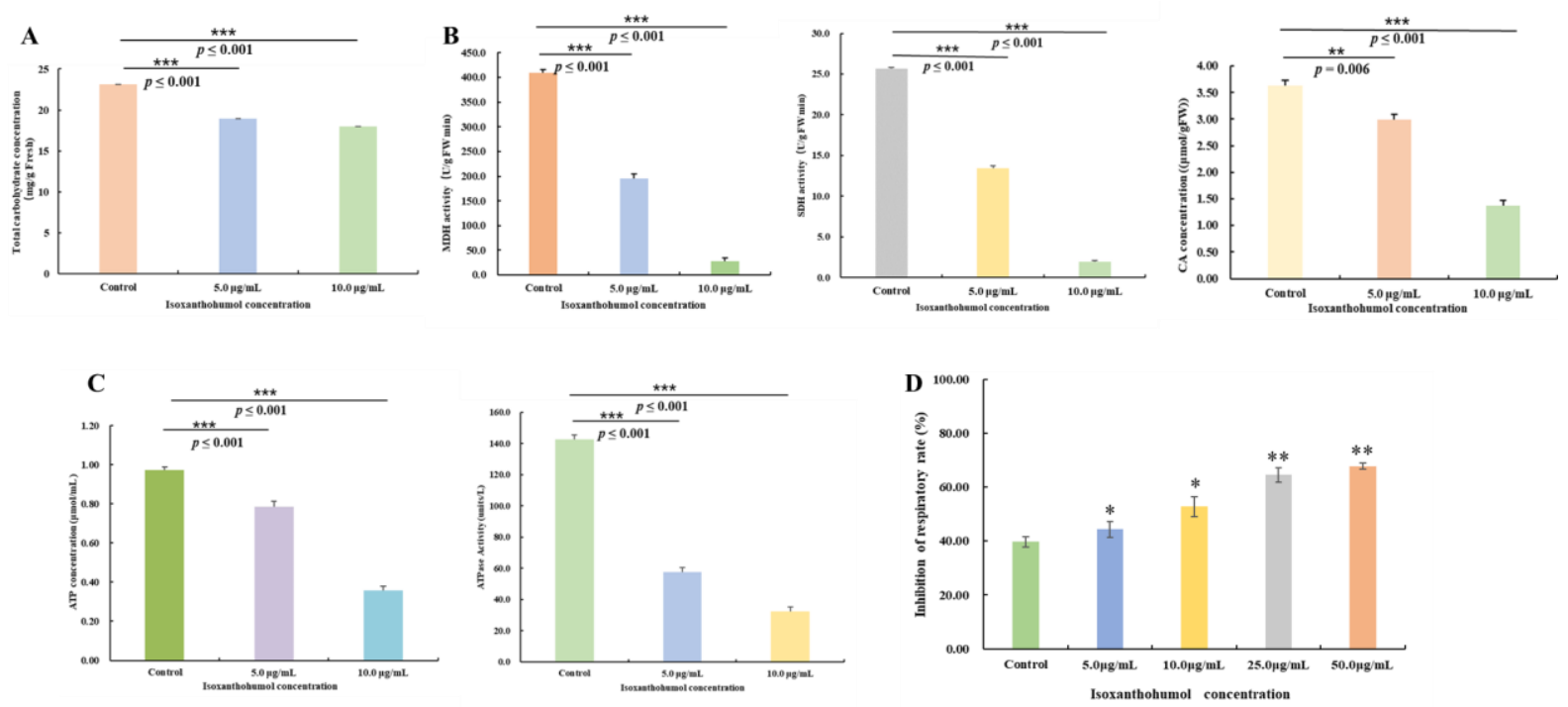

Figure 9. (A) Effect of isoxanthohumol on the total carbohydrate content of B. cinerea; (B) Effects of isoxanthohumol on the dehydrogenase activities and CA content of B. cinerea; (C) Effects of isoxanthohumol on the ATP content and ATPase activity of B. cinerea; (D) Inhibition rate of isoxanthohumol on cell respiration of B. cinerea mycelia. ${ }^{*} p<0.05,{ }^{* *} p<0.01$ and *** $p<0.001$.

Considering that the intracellular ATP content directly affects the normal energy metabolism of pathogenic fungi, is a general energy source for all living cells, and provides direct energy for various life activities of organisms [25], the effects of isoxanthohumol on ATP content and ATPase activity were also studied. As shown in Figure 9C, the ATP content in B. cinerea was $0.9737 \mu \mathrm{mol} / \mathrm{mL}$ in the blank control; when treated with 5.0 and $10.0 \mu \mathrm{g} / \mathrm{mL}$ of isoxanthohumol, the ATP content reduced to $0.7859 \mu \mathrm{mol} / \mathrm{mL}$ and $0.3590 \mu \mathrm{mol} / \mathrm{mL}$, respectively, and ATPase activity was decreased by $59.74 \%$ and $77.29 \%$, respectively, at the same concentrations.

In general, the respiration of pathogenic fungi functions by absorbing oxygen to release energy, some of which is stored as ATP. In addition, respiratory metabolism can improve the vitality of pathogenic fungi [17]. The effect of isoxanthohumol on cell respiration is shown in Figure 9D. The isoxanthohumol decreased the respiration of B. cinerea in a concentrationdependent manner. After treatment with isoxanthohumol for $24 \mathrm{~h}$ at concentrations of $5.0,10.0,25.0$, and $50.0 \mu \mathrm{g} / \mathrm{mL}$, the inhibition rates of respiration were $44.31 \%, 52.78 \%$, $64.47 \%$, and $67.75 \%$, respectively. This indicated that the respiration of B. cinerea was significantly inhibited by isoxanthohumol compared with the blank control $(p<0.05)$. All of these results together demonstrate that isoxanthohumol affects the carbohydrate metabolic process, destroys the TCA cycle, and hinders the generation of ATP by inhibiting respiration, thus accelerating the death of $B$. cinerea.

\subsection{Changes Due to Isoxanthohumol in B. cinerea Cell Membrane}

The relative electric conductivity of the culture medium is used to reflect the cell membrane permeability of mycelia [26], and the permeability and fluidity of the cell membrane are of considerable significance to the survival of cells. Previous research demonstrated that flavonoids exert their antifungal activity by destroying the cytoplasmic membrane [27], and xanthohumol could also increase membrane permeability in HL-60 cells [28]. Isoxanthohumol is the main isoprene flavonoid in H. lupulus, and the morphology results in our study also showed that isoxanthohumol caused obvious damage to the cell membrane of B. cinerea (Figure 10). Therefore, we speculate that isoxanthohumol may also exert antifungal activity by destroying the cell membrane. Figure 10A shows that the 
relative electrical conductivity was increased in a dose-dependent and time-dependent manner. Although the discrepancy in the relative electric conductivity was not significant in the initial $4 \mathrm{~h}$, the relative electric conductivity in the treatment with $50.0 \mu \mathrm{g} / \mathrm{mL}$ of isoxanthohumol was significantly higher than those for all of the other, lower concentrations in the subsequent time period.
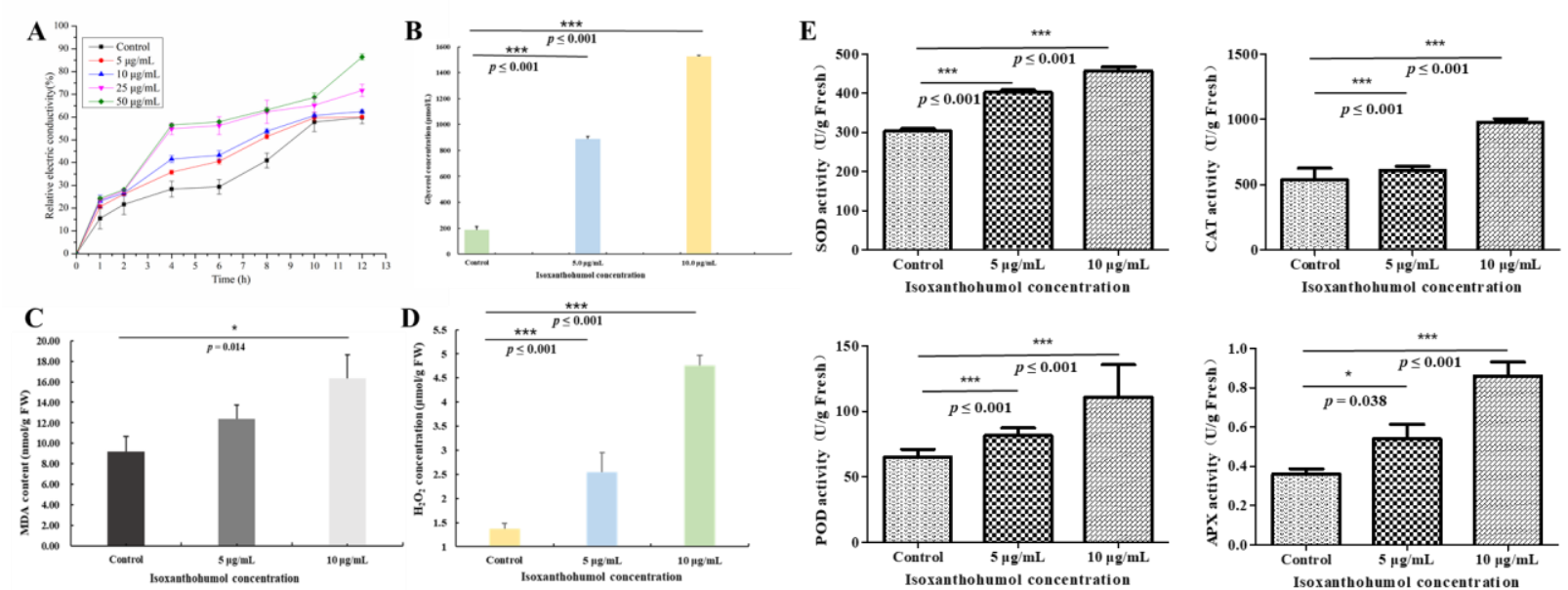

Figure 10. (A) Effect of isoxanthohumol on the cell membrane permeability of B. cinerea mycelia; (B) Effect of isoxanthohumol on the glycerol content of B. cinerea; (C) Effect of isoxanthohumol on the MDA content of B. cinerea (D) Effect of isoxanthohumol on the $\mathrm{H}_{2} \mathrm{O}_{2}$ content of $B$. cinerea; (E) Effect of isoxanthohumol on the activity of antioxidant-related enzymes of $B$. cinerea. ${ }^{*} p<0.05$ and ${ }^{* * *} p<0.001$.

The cell membrane is essential for the normal growth of cells, and destruction of the cell membrane causes high osmotic pressure [29]. It has been demonstrated that intracellular glycerol plays an important role in the response to osmotic stress, and the process of osmotic adaptation by activation of the HOG pathway results in the biosynthesis and accumulation of glycerol to balance the osmotic pressure [30]. To further verify whether isoxanthohumol affected osmotic stress, we tested the change in glycerol content. As shown in Figure 10B, the intracellular glycerol content increased most significantly in isoxanthohumol-treated B. cinerea compared with the blank control $(p<0.001)$. This indicated that isoxanthohumol induced cell membrane damage in B. cinerea.

\subsection{Effect of Isoxanthohumol on Membrane Lipid Peroxidation of B. cinerea}

MDA is one of the main indexes of lipid peroxidation, and its content is usually used as an indicator of oxidative stress. The formation of MDA results in the loss of cell membrane integrity and damage to pathogenic fungi [31]. As shown in Figure 10C, the MDA content in B. cinerea increased significantly after treatment with 5 and $10 \mu \mathrm{g} / \mathrm{mL}$ of isoxanthohumol $(p<0.05)$. The membrane lipid peroxidation of $B$. cinerea mycelia in this study may be related to the changes in MDA content.

$\mathrm{H}_{2} \mathrm{O}_{2}$ is a kind of reactive oxygen species; it is effective at eliciting a signaling response to enhance the tolerance and defense ability of mycelia, but it may cause oxidative damage to lipids, proteins, and nucleic acid molecules [32]. As illustrated in Figure 10D, the $\mathrm{H}_{2} \mathrm{O}_{2}$ content of $B$. cinerea mycelia was increased in a dose-dependent manner. After treatment with $5.0 \mu \mathrm{g} / \mathrm{mL}$ and $10.0 \mu \mathrm{g} / \mathrm{mL}$ of isoxanthohumol, $\mathrm{H}_{2} \mathrm{O}_{2}$ contents were increased by $46.40 \%$ and $71.20 \%$, respectively. This result indicates that the membrane lipid peroxidation of $B$. cinerea mycelia may be associated with an increase in $\mathrm{H}_{2} \mathrm{O}_{2}$ content.

The $\mathrm{H}_{2} \mathrm{O}_{2}$ content changes with the activity of antioxidant enzymes, including SOD, CAT, POD, and APX enzymes [4], and the antioxidant enzymes can be used to reflect whether mycelia are damaged by membrane lipid peroxidation [31]. As shown in Figure 10E, antioxidant-related enzymes of $B$. cinerea mycelia were increased in a dose-dependent manner, and the most significant difference in SOD, CAT, POD, and APX activity was observed 
between the isoxanthohumol treatment and blank control $(p<0.001)$. All of these results demonstrated that isoxanthohumol may cause the destruction of the cell membrane by membrane lipid peroxidation, which causes final damage to B. cinerea mycelia.

\section{Materials and Methods}

\subsection{Pathogenic Fungi and Reagents}

Isoxanthohumol (CAS-No. 70872-29-6; 98\%) was purchased from Sichuan Weikeqi Biological Technology Co., Ltd. (Chengdu, China). The Fungal RNA kit was purchased from Beijing Noble Technology Co., Ltd. (Beijing, China). The one-step RT-PCR kit and SuperReal PreMix (SYBR Green) were purchased from Tiangen Biotech (Beijing, China) Co., Ltd. The yeast mitochondria isolation kit and ATP colorimetric/fluorometric assay kit were purchased from Biovision (San Francisco, CA, USA). The ATPase/GTPase activity assay kit was purchased from Sigma-Aldrich (St. Louis, MO, USA). The BCA protein assay kit, NAD-malate dehydrogenase (NAD-MDH) assay kit, micro succinate dehydrogenase (SDH) assay kit, citric acid (CA) content assay kit, total carbohydrate colorimetric assay kit, micro malondialdehyde (MDA) assay kit, micro hydrogen peroxide $\left(\mathrm{H}_{2} \mathrm{O}_{2}\right)$ assay kit, superoxide dismutase (SOD) assay kit, micro catalase (CAT) assay kit, micro peroxidase (POD) assay kit, and micro ascorbate peroxidase (APX) assay kit were purchased from Solarbio (Beijing, China). The glycerol assay kit was purchased from Nanjing Jiancheng Bioengineering Institute (Nanjing, China). H. lupulus Linn. was provided by Shaanxi Fangsheng Medical Technology Co., Ltd. (Hanzhong, China) and was identified by Prof. Yang Zhigang. The voucher specimen was submitted to the herbarium of the Lanzhou Institute of Pharmacology (Lanzhou University, China).

Five pathogenic fungus isolations-Rhizoctonia solani, Sclerotinia sclerotiorum, Botrytis cinerea, Fusarium graminearum, and Magnaporthe oryzae - were provided by the Institute of Plant Protection, Gansu Academy of Agricultural Science. The fungi were cultured in potato dextrose agar medium (PDA) at $23 \pm 2{ }^{\circ} \mathrm{C}$ for a week to obtain new mycelia for the antifungal assay.

\subsection{H. lupulus Extracts and HPLC Analysis}

The powdered material of $H$. lupulus ( $40.00 \mathrm{~g}$ ) was ultrasonically extracted three times with $80 \%$ ethanol $(480 \mathrm{~mL} \times 3.25 \mathrm{~h} \times 3)$ at $65{ }^{\circ} \mathrm{C}$. The ethanolic extract was combined, filtered, and concentrated at $45^{\circ} \mathrm{C}$ under reduced pressure [33]. The extract was obtained after evaporation.

The sample was filtered using a nylon membrane $(0.22 \mu \mathrm{m}$ pore size). Then, $1.0 \mathrm{~mL}$ of the standard and extract were placed in vials for analysis by HPLC at $30{ }^{\circ} \mathrm{C}$ with a UV-vis photodiode array detector at $288 \mathrm{~nm}$ (1260 Infinity II, Agilent, Santa Clara, CA, USA). Determination was performed under the following operating conditions: a reversedphase column (C18, $4.6 \mathrm{~mm} \times 150 \mathrm{~mm}$; particle size $5 \mu \mathrm{m}$, Agilent, Santa Clara, CA, USA, ZORBAX SB-C18); mobile phase of acetonitrile $/ 1 \%$ formic acid solution in gradient elution (0 20 min: 40-60, 20 25 min: 100-0, 25 28 min: 40-60, 28 33 min: 40-60, v/v) at a flow rate of $0.8 \mathrm{~mL} / \mathrm{min}$; and an injection volume of $5 \mu \mathrm{L}$. Finally, the content of isoxanthohumol in H. lupulus was calculated based on the obtained calibration curve.

\subsection{In Vitro Antifungal Activity}

The mycelium growth inhibition method was used to evaluate the in vitro antifungal activity of the ethanolic extract of $H$. lupulus and isoxanthohumol. In this method, extract and isoxanthohumol were dissolved in dimethyl sulfoxide (DMSO) and then added to PDA medium to obtain sterile media of different concentrations. Boscalid and 0.5\% DMSO $(v / v)$ were used as a positive control and blank control, respectively. A $5 \mathrm{~mm}$ agar plug of each fungal strain, obtained from a 3-day-old PDA culture, was inoculated in the middle of PDA plates containing DMSO or samples. Petri dishes were incubated at $23 \pm 2{ }^{\circ} \mathrm{C}$ in darkness, and radial growth was recorded by measuring the cross diameters of three replicates. 
The antifungal activity in vitro was expressed as the $\mathrm{EC}_{50}$ value, and the mycelial growth inhibition rate was calculated by the following formula:

$$
\text { Mycelial growth inhibition }(\%)=[(\mathrm{dc}-\mathrm{dt}) /(\mathrm{dc}-5 \mathrm{~mm})] \times 100
$$

where $\mathrm{dc}$ and $\mathrm{dt}$ are the average diameters of the control and treatment fungal colonies, respectively.

\subsection{In Vivo Antifungal Activity}

To prepare test solutions at concentrations of $200 \mu \mathrm{g} / \mathrm{mL}, 100 \mu \mathrm{g} / \mathrm{mL}$, and $50 \mu \mathrm{g} / \mathrm{mL}$, isoxanthohumol was dissolved in DMSO, followed by dilution with water containing Tween 20 (Solarbio, Beijing, China). Next, cherry tomatoes all similar in size and growth status and without infection by pathogens were selected and washed with clean water, surface sterilized with $2 \% \mathrm{NaOCl}$ for $5 \mathrm{~min}$, and rinsed three times in sterile water. A $3 \mathrm{~mm}$ deep hole was pricked on the skin of each cherry tomato, and a drop of sample solution $(10 \mu \mathrm{L})$ was injected into it. Boscalid (Solarbio, Beijing, China) and 0.5\% DMSO $(v / v)$ were used as a positive control and blank control, respectively. Twenty-four hours later, $5 \mu \mathrm{L}$ of conidia $\left(1 \times 10^{5} \sim 1 \times 10^{6}\right.$ spores $\left./ \mathrm{mL}\right)$ was inoculated. After that, cherry tomatoes were placed in an artificial climate chamber at $23 \pm 2{ }^{\circ} \mathrm{C}$ and $85 \%$ relative humidity for 7 days (Tao et al., 2020). For curative efficacy, $5 \mu \mathrm{L}$ of conidia was inoculated before isoxanthohumol solution was injected. All experiments for in vivo antifungal activity were run in triplicate, and the protective efficacy or curative efficacy was calculated.

\subsection{Effect of Isoxanthohumol on B. cinerea Spore Germination}

A spore suspension of $B$. cinerea was obtained from 10-day-old cultures and mixed with sterile distilled water to obtain a homogeneous spore suspension of $1 \times 10^{6}$ spores $/ \mathrm{mL}$. A $100 \mu \mathrm{L}$ spore suspension of B. cinerea was placed on a depression slide containing $100 \mu \mathrm{L}$ of different concentrations of isoxanthohumol and added 1\% DMSO, with sterile distilled water as a blank control. The inoculated glass slides were incubated in a digital biochemical incubator at $23 \pm 2{ }^{\circ} \mathrm{C}$. Spore germination was observed under the microscope at $8 \mathrm{~h}$ after inoculation [3]. Each experiment was performed three times, and the inhibition rate of spore germination was calculated.

\subsection{Scanning Electron Microscopy (SEM) Observations}

The effect of isoxanthohumol on the morphological characteristics of B. cinerea was observed using a scanning electron microscope (SEM). A sample was obtained from the colonies of 3-day-old cultures and fixed with $2.5 \%$ glutaraldehyde for $4 \mathrm{~h}$, then washed three times with $0.1 \mathrm{M}$ phosphate buffer ( $\mathrm{pH}$ 7.2) for $10 \mathrm{~min}$ each time. The sample was post-fixed with $1 \%$ osmium tetraoxide solution for another $2 \mathrm{~h}$, then dehydrated in an ethanol gradient of $20 \%, 50 \%, 80 \%$, and $100 \%$ for $10 \sim 15$ min each. Finally, the sample was critical point dried and then coated with gold. It was visualized under a scanning electron microscope (Hitachi, S-3400N, Tokyo, Japan) at an accelerating voltage of $15.0 \mathrm{kV}$.

\subsection{Transmission Electron Microscopy (TEM) Observations}

The mycelium was prepared, as mentioned above, for examination under transmission electron microscope (TEM). The sample was pre-fixed in $2.5 \%$ glutaraldehyde in $0.1 \mathrm{M}$ phosphate buffer ( $\mathrm{pH} 7.2$ ) for $4 \mathrm{~h}$ at $23 \pm 2{ }^{\circ} \mathrm{C}$, and then washed three times in $0.1 \mathrm{M}$ phosphate buffer for 10 min each. The mycelium was post-fixed in $1 \%$ osmium tetroxide for another $2 \mathrm{~h}$ and dehydrated in a graded series of ethanol and acetone. Finally, it was embedded in Epon 812 (Sigma Aldrich, St. Louis, MO, USA) and polymerized in Spurr's resin at $60{ }^{\circ} \mathrm{C}$ for $48 \mathrm{~h}$. The specimen block was sectioned to $70 \mathrm{~nm}$ thickness, then doublestained with uranyl acetate and lead citrate. The stained section was examined via TEM (JEM-1010 transmission electron microscopy; NEC, Tokyo, Japan). 


\subsection{Transcriptome Analysis}

The B. cinerea mycelia used in this experiment were obtained from cultures on PD medium for $3 \mathrm{~d}$. An agar plug of $B$. cinerea strain from a 3-day-old PDA culture was added to PD medium containing $5 \mu \mathrm{g} / \mathrm{mL}$ of isoxanthohumol used as treatment, and $0.5 \%$ DMSO $(v / v)$ was used as a blank control simultaneously. Each group contained three biological replicates, and the harvested mycelia were quickly frozen in liquid nitrogen. The total RNA extraction, quantification, qualification, cDNA library construction, and transcriptome sequencing were completed using a service from Beijing Genomics Institute (BGI) Co., Ltd. (Shenzhen, China). The sample was sequenced on the BGIseq500 platform (BGI-Shenzhen, China).

\subsection{Verification of $D E G s$ by $R T-q P C R$}

Seven random DEGs related to carbon metabolism or the citrate cycle (TCA cycle) were validated by RT-qPCR with three replicates to verify the transcriptome data. The total RNA extracted was determined as described using RNA isolation solvent (Omega Bio-tek, Norcross, GA, USA). For the reverse transcription reaction, cDNA was synthesized from 500 ng of total RNA using a FastKing gDNA Dispelling RT SuperMix kit (Tiangen Biotech Co., Ltd., Beijing, China) according to the manufacturer's instructions. Real-time fluorescence quantitative PCR (qPCR) was performed using a SuperReal PreMix Plus (SYBR Green) kit (Tiangen Biotech Co., Ltd., Beijing, China) according to the manufacturer's instructions. The PCR reaction was conducted as follows: $95{ }^{\circ} \mathrm{C}$ for $15 \mathrm{~min}$, followed by 40 cycles of $95^{\circ} \mathrm{C}$ for $10 \mathrm{~s}$ and $60{ }^{\circ} \mathrm{C}$ for $32 \mathrm{~s}$. Sequences of the primers used in RT-qPCR assays are listed in Supplementary Table S2. The relative expression of the target genes was calculated via the $2^{-\Delta \Delta} \mathrm{Ct}$ method. All of the PCR reactions were performed at least three times.

\subsection{Determination of Total Carbohydrate Content}

For the determination of the total carbohydrate content, $B$. cinerea mycelia treated with $5.0 \mu \mathrm{g} / \mathrm{mL}$ and $10.0 \mu \mathrm{g} / \mathrm{mL}$ of isoxanthohumol were used as the treatment group, and the mycelia treated with DMSO were used as a blank control. The effect of isoxanthohumol on the carbohydrate content was determined according to the previously described method [2] using a total carbohydrate content assay kit (Solarbio, Beijing, China). In brief, the harvested mycelium was used to extract total carbohydrates, and the standard curve was prepared. The content of carbohydrate was expressed as milligrams per gram on a fresh weight basis.

\subsection{Determination of Dehydrogenase Activities and CA Content}

Dehydrogenase activities and CA content were measured by a previous method with minor modifications [34]. Mycelia were collected using the above methods. The activities of MDH and SDH were measured using an NAD-malate dehydrogenase assay kit (Solarbio, Beijing, China) and a micro succinate dehydrogenase assay kit (Solarbio, Beijing, China), respectively. One unit is the consumption amount of $1 \mathrm{nmoL} 2$, 6-dichlorophenol indophenol or NADH per minute under the assay conditions. The content of CA was assessed using a citric acid content detection kit (Solarbio, Beijing, China). All operations were accomplished according to the manufacturer's recommendation, and each experiment was run at least three times.

\subsection{Determination of ATP Content and ATPase Activity}

For the determination of the ATP content and ATPase activity, mitochondria were isolated using a yeast mitochondria isolation kit (Biovision, San Francisco, CA, USA), and the content of protein was determined using a BCA protein assay kit (Solarbio, Beijing, China). Then, the ATP content and ATPase activity of the mitochondria were determined using an ATP Colorimetric/Fluorometric assay kit and an ATPase/GTPase activity assay kit, respectively. All operations were performed according to the manufacturer's instruction, and each experiment was performed at least three times. 


\subsection{Determination of Cell Respiration}

The effect of isoxanthohumol on the respiration rate was assessed using a Dissolved Oxygen Meter (JPSJ-606L Dissolved Oxygen Meter; LEICI, Shanghai, China) by the methods of (Yan et al., 2020b). Firstly, B. cinerea was cultured for three days to obtain mycelia. Then, different concentrations of isoxanthohumol were added to $40 \mathrm{~mL}$ of PBS solution containing $1 \%$ glucose, and $200.00 \mathrm{mg}$ of mycelia was suspended in PBS solution. Finally, the dissolved oxygen content was recorded for $24 \mathrm{~h}$. The experiment was performed three times. The respiration rate of $B$. cinerea was calculated by the following formula:

$$
\text { Inhibition rate }(\%)=\left[1-\left(\mathrm{R}_{0}-\mathrm{R}_{1}\right) / \mathrm{R}_{0}\right] \times 100
$$

where $R_{0}$ is the dissolved oxygen content at $0 h$, and $R_{1}$ is the dissolved oxygen content at $0.5 \sim 24 \mathrm{~h}$.

\subsection{Cell Membrane Permeability}

The cell membrane permeability of $B$. cinerea was evaluated by measuring the relative electrical conductivity. In brief, $B$. cinerea was added to the PD medium and then incubated at $23 \pm 2{ }^{\circ} \mathrm{C}$ for 3 days to obtain the sample. Then, $400.00 \mathrm{mg}$ of mycelia was suspended in $40 \mathrm{~mL}$ of sterile distilled water with $5.0,10.0,25.0$, or $50.0 \mu \mathrm{g} / \mathrm{mL}$ of isoxanthohumol as the treatment group; at the same time, $0.5 \% \operatorname{DMSO}(v / v)$ was used as a blank control. Finally, the conductivity of the suspension was determined using a conductivity detector (HORIBA EC1100, HORIBA Advanced Techno Co., Ltd., Osaka, Japan) (conductivity at $0 \mathrm{~h}$ was marked as L0, and that at $0.5-12 \mathrm{~h}$ was marked as L1). After the mycelia were boiled for $30 \mathrm{~min}$, the final electric conductivity was measured and marked as L2. The relative permeability rate of mycelia was calculated by the following formula:

$$
\text { Relative electric conductivity }(\%)=[(\mathrm{L} 1-\mathrm{L} 0) /(\mathrm{L} 2-\mathrm{L} 0)] \times 100
$$

\subsection{Determination of Glycerol Content}

The glycerol content in the sample was determined using a glycerol assay kit (Nanjing Jiancheng Bioengineering Institute, Nanjing, China). B. cinerea was cultured in PD medium at $23 \pm 2{ }^{\circ} \mathrm{C}$ for 3 days to obtain mycelia. Then, the extraction and determination of glycerol were performed according to the manufacturer's instructions, and each experiment was repeated at least three times.

\subsection{Determination of MDA Content}

The content of MDA was examined using a micro malondialdehyde assay kit (Solarbio, Beijing, China). After the sample was collected, all operations were carried out according to the manufacturer's instruction. Each experiment was performed in three replicates.

\subsection{Determination of $\mathrm{H}_{2} \mathrm{O}_{2}$ Content}

The hydrogen peroxide content was measured using a micro hydrogen peroxide assay kit (Solarbio, Beijing, China). All operations were carried out following the manufacturer's instructions. The sample was collected as described above, and each experiment was repeated at least three times.

\subsection{Activity of Antioxidant-Related Enzymes}

The activity of antioxidant-related enzymes, including SOD, CAT, POD, and APX, was measured using different commercial kits (BC0175, BC0205, BC0095, BC0225, respectively; Solarbio, Beijing, China) [26]. After the extraction, the suspension was centrifuged, and the activity was measured according to the manufacturer's instructions.

\subsection{Statistical Analysis}

The data were reported as mean \pm standard deviations, and significant differences between mean values were evaluated via Tukey's multiple range test, followed by one-way 
ANOVA $\left({ }^{*} p<0.05,{ }^{* *} p<0.01,{ }^{* * *} p<0.001\right)$. All the statistical analyses were carried out using SPSS (IBM, Amonk, NY, USA) software version 24.0.

\section{Conclusions}

In conclusion, the results of this study show that the ethanolic extract of H. lupulus, a medicinal and edible plant, exhibited moderate antifungal activity against the five tested phytopathogenic fungi in vitro. Isoxanthohumol was found to possess strong antifungal activity against $B$. cinerea with an $\mathrm{EC}_{50}$ value of $4.32 \mu \mathrm{g} / \mathrm{mL}$; therefore, the antifungal mechanism of isoxanthohumol on $B$. cinerea was studied systematically. The present data suggest that the antifungal mechanism of isoxanthohumol is mainly related to metabolism; it affected the carbohydrate metabolic process, destroyed the TCA cycle, and hindered the generation of ATP by inhibiting respiration. In addition, isoxanthohumol also affected the membrane system, induced by membrane lipid peroxidation, thus accelerating the death of B. cinerea mycelia. This study demonstrates that isoxanthohumol can be used as a potential botanical fungicide for the management of phytopathogenic fungi. To our knowledge, this work is the first report on the antifungal mechanism of isoxanthohumol against $B$. cinerea.

Supplementary Materials: The following are available online at https: / www.mdpi.com/article/ 10.3390/ijms221910853/s1. Table S1: Key DEGs involved in Carbon metabolism and TCA cycle and their primer sequences. Table S2: Inhibition of mycelium of three plant pathogenic fungi by isoxanthohumol.

Author Contributions: Writing—original draft preparation, Y.-F.Y., T.-L.W. and Z.-J.Z.; methodology, Y.-F.Y., S.-S.D., Z.-R.W. and Y.-M.H.; writing-review and editing, Y.-F.Y., T.-L.W., Z.-J.Z., W.-B.Z. and C.-J.Y.; supervision, Z.-J.Z. and Y.-Q.L. All authors have read and agreed to the published version of the manuscript.

Funding: This work was supported financially by the National Natural Science Foundation of China $(21877056,21672092)$ and the National Key Research and Development Program of China (2017YFD0201404); Support was also supplied by the Key Program for international S\&T cooperation projects of China Gansu Province (18YF1WA115).

Institutional Review Board Statement: Not applicable.

Informed Consent Statement: Not applicable.

Data Availability Statement: All data are contained within this manuscript.

Conflicts of Interest: The authors declare no conflict of interest.

\section{References}

1. Liang, C.; Yang, L.; Shao, Y.; Zhu, X.Y.; Zhao, H.L.; Chen, B.W.; Song, W.; Song, X.M.; Ding, X.F.; Sun, R.F. Broad-spectrum antifungal activity of dichloromethane extract of Waltheria indica stems and isolated compounds. Ind. Crop. Prod. 2019, 142, 111855. [CrossRef]

2. Liu, T.T.; Wu, H.B.; Wu, H.B.; Zhang, J. Wormwood (Artemisia absinthium L.) as a promising nematicidal and antifungal agent: Chemical composition, comparison of extraction techniques and bioassay-guided isolation. Ind. Crop. Prod. 2019, 133, $295-303$. [CrossRef]

3. Bi, Y.H.; Yu, Z.G. Diterpenoids from Streptomyces sp. SN194 and their antifungal activity against Botrytis cinerea. J. Agric. Food Chem. 2016, 64, 8525-8529. [CrossRef]

4. Yang, Q.; Wang, J.; Zhang, P.; Xie, S.N.; Yuan, X.L.; Hou, X.D.; Yan, N.; Fang, Y.D.; Du, Y.M. In vitro and in vivo antifungal activity and preliminary mechanism of cembratrien-diols against Botrytis cinerea. Ind. Crop. Prod. 2020, 154, 112745. [CrossRef]

5. Kumar, A.; Kujur, A.; Yadav, A.; Pratap, S.; Prakash, B. Optimization and mechanistic investigations on antifungal and aflatoxin B1 inhibitory potential of nanoencapsulated plant-based bioactive compounds. Ind. Crop. Prod. 2019, 131, 213-223. [CrossRef]

6. Danielli, L.J.; Pippi, B.; Soares, K.D.; Duarte, J.A.; Maciel, A.J.; Machado, M.M.; Oliveira, L.F.S.; Bordignon, S.A.L.; Fuentefria, A.M.; Apel, M.A. Chemosensitization of filamentous fungi to antifungal agents using Nectandra Rol. ex Rottb. species essential oils. Ind. Crop. Prod. 2017, 102, 7-15. [CrossRef]

7. Dan, W.J.; Tuong, T.M.L.; Wang, D.C.; Li, D.; Zhang, A.L.; Gao, J.M. Natural products as sources of new fungicides (V): Design and synthesis of acetophenone derivatives against phytopathogenic fungi in vitro and in vivo. Bioorg. Med. Chem. Lett. 2018, 28, 2861-2864. [CrossRef] [PubMed] 
8. Ammar, M.I.; Nenaah, G.E.; Mohamed, A.H.H. Antifungal activity of prenylated flavonoids isolated from Tephrosia apollinea L. against four phytopathogenic fungi. Crop Prot. 2013, 49, 21-25. [CrossRef]

9. Di Liberto, M.G.; Stegmayer, M.I.; Svetaz, L.A.; Derita, M.G. Evaluation of Argentinean medicinal plants and isolation of their bioactive compounds as an alternative for the control of postharvest fruits phytopathogenic fungi. Rev. Bras. Farmacogn. 2019, 29, 686-688. [CrossRef]

10. Wang, S.; Dunlap, T.L.; Howell, C.E.; Mbachu, O.C.; Rue, E.A.; Phansalkar, R.; Chen, S.N.; Pauli, G.F.; Dietz, B.M.; Bolton, J.L. Hop (Humulus lupulus L.) extract and 6-prenylnaringenin induce P450 1A1 catalyzed estrogen 2-hydroxylation. Chem. Res. Toxicol. 2016, 29, 1142-1150. [CrossRef] [PubMed]

11. Bocquet, L.; Sahpaz, S.; Hilbert, J.L.; Rambaud, C.; Rivière, C. Humulus lupulus L., a very popular beer ingredient and medicinal plant: Overview of its phytochemistry, its bioactivity, and its biotechnology. Phytochem. Rev. 2018, 17, 1047-1090. [CrossRef]

12. Karabín, M.; Hudcová, T.; Jelínek, L.; Dostálek, P. Biologically active compounds from hops and prospects for their use. Compr. Rev. Food Sci. Food Saf. 2016, 15, 542-567. [CrossRef]

13. Kramer, B.; Mignard, C.; Warschat, D.; Gürbüz, S.; Aiglstorfer, P.; Muranyi, P. Inhibition of Listeria monocytogenes on bologna by a beta acid rich hop extract. Food Control 2021, 126, 108040. [CrossRef]

14. Mizobuchi, S.; Sato, Y. A new flavanone with antifungal activity isolated from hops. Agric. Biol. Chem. 1984, 48, $2771-2775$.

15. Bocquet, L.; Rivière, C.; Dermont, C.; Samaillie, J.; Hilbert, J.H.; Halama, P.; Siah, A.; Sahpaz, S. Antifungal activity of hop extracts and compounds against the wheat pathogen Zymoseptoria tritici. Ind. Crop. Prod. 2018, 122, 290-297. [CrossRef]

16. Bartmańska, A.; Wałecka-Zacharska, E.; Tronina, T.; Popłoński, J.; Sordon, S.; Brzezowska, E.; Bania, J.; Huszcza, E. Antimicrobial properties of spent hops extracts, flavonoids isolated therefrom, and their derivatives. Molecules 2018, 23, 2059. [CrossRef]

17. Feng, T.Y.; Li, J.L.; Sun, M.F.; Peng, J.N.; Li, X.H.; Qi, Z.Q. SYAUP-CN-26 applies its antifungal activity against Botrytis cinerea by disrupting mitochondrial structure and function. Biochimie 2020, 176, 162-168. [CrossRef] [PubMed]

18. Nikolic, D.; Li, Y.M.; Chadwick, L.R.; Pauli, G.F.; van Breemen, R.B. Metabolism of xanthohumol and isoxanthohumol, prenylated flavonoids from hops (Humulus lupulus L.), by human liver microsomes. J. Mass Spectrom. 2005, 40, 289-299. [CrossRef]

19. Karabulut, O.A.; Romanazzi, G.; Smilanick, J.L.; Lichter, A. Postharvest ethanol and potassium sorbate treatments of table grapes to control gray mold. Postharvest Biol. Technol. 2005, 37, 129-134. [CrossRef]

20. Huang, K.; Zhang, B.; Chen, Y.; Liu, Z.Q.; Zheng, Y.G. Comparative transcriptome analysis of Streptomyces nodosus mutant with a high-yield amphotericin B. Front. Bioeng. Biotechnol. 2021, 8, 621431. [CrossRef]

21. Lai, T.F.; Sun, Y.Y.; Liu, Y.Y.; Li, R.; Chen, Y.Z.; Zhou, T. Cinnamon oil inhibits Penicillium expansum growth by disturbing the carbohydrate metabolic process. J. Fungi 2021, 7, 123. [CrossRef]

22. Lee, J.S.; Oh, S.J.; Choi, H.J.; Kang, J.H.; Lee, S.H.; Ha, J.S.; Woo, S.M.; Jang, H.; Lee, H.; Kim, S.Y. ATP production relies on fatty acid oxidation rather than glycolysis in pancreatic ductal adenocarcinoma. Cancers 2020, 12, 2477. [CrossRef] [PubMed]

23. Li, Y.H.; Shao, X.F.; Xu, J.Y.; Wei, Y.Y.; Xu, F.; Wang, H.F. Tea tree oil exhibits antifungal activity against Botrytis cinerea by affecting mitochondria. Food Chem. 2017, 234, 62-67. [CrossRef] [PubMed]

24. Ma, Y.Z.; Yu, H.H.; Liu, W.X.; Qin, Y.K.; Xing, R.G.; Li, P.C. Integrated proteomics and metabolomics analysis reveals the antifungal mechanism of the C-coordinated O-carboxymethyl chitosan Cu(II) complex. Int. J. Biol. Macromol. 2020, 155, 1491-1509. [CrossRef] [PubMed]

25. Zhang, Y.; Li, T.J.; Xu, M.J.; Guo, J.H.; Zhang, C.M.; Feng, Z.Z.; Peng, X.; Li, Z.Y.; Xing, K.; Qin, S. Antifungal effect of volatile organic compounds produced by Pseudomonas chlororaphis subsp. aureofaciens SPS-41 on oxidative stress and mitochondrial dysfunction of Ceratocystis fimbriata. Pestic. Biochem. Physiol. 2021, 173, 104777. [CrossRef]

26. Yang, R.P.; Miao, J.Y.; Shen, Y.T.; Cai, N.; Wan, C.P.; Zou, L.Q.; Chen, C.Y.; Chen, J.J. Antifungal effect of cinnamaldehyde, eugenol and carvacrol nanoemulsion against Penicillium digitatum and application in postharvest preservation of citrus fruit. LWT-Food Sci. Technol. 2021, 141, 110924. [CrossRef]

27. Chu, W.C.; Bai, P.Y.; Yang, Z.Q.; Cui, D.Y.; Hua, Y.G.; Yang, Y.; Yang, Q.Q.; Zhang, E.; Qin, S.S. Synthesis and antibacterial evaluation of novel cationic chalcone derivatives possessing broad spectrum antibacterial activity. Eur. J. Med. Chem. 2018, 143, 905-921. [CrossRef]

28. Wang, C.M.; Huo, X.; Chen, J.; Liu, J.W.; Yang, T.Y.; Mi, X.Q.; Meng, Y.; Zhou, L.; Lin, C.J.; Liu, J. An acute lytic cell death induced by xanthohumol obstructed ROS detecting in HL-60 cells. Toxicol. In Vitro 2019, 62, 104667. [CrossRef]

29. Wang, B.; Liu, F.; Li, Q.; Xu, S.; Zhao, X.Z.; Xue, P.L.; Feng, X. Antifungal activity of zedoary turmeric oil against Phytophthora capsici through damaging cell membrane. Pestic. Biochem. Physiol. 2019, 159, 59-67. [CrossRef]

30. Duran, R.; Cary, J.W.; Calvo, A.M. Role of the osmotic stress regulatory pathway in morphogenesis and secondary metabolism in filamentous fungi. Toxins 2010, 2, 367-381. [CrossRef]

31. Zhang, C.; Zhao, J.C.; Famous, E.; Pan, S.Y.; Peng, X.; Tian, J. Antioxidant, hepatoprotective and antifungal activities of black pepper (Piper nigrum L.) essential oil. Food Chem. 2021, 346, 128845. [CrossRef] [PubMed]

32. Veal, E.A.; Day, A.M.; Morgan, B.A. Hydrogen peroxide sensing and signaling. Mol. Cell 2007, 26, 1-14. [CrossRef] [PubMed]

33. Kontek, B.; Jedrejek, D.; Oleszek, W.; Olas, B. Antiradical and antioxidant activity in vitro of hops-derived extracts rich in bitter acids and xanthohumol. Ind. Crop. Prod. 2021, 161, 113208. [CrossRef]

34. Kong, J.; Xie, Y.F.; Yu, H.; Guo, Y.H.; Cheng, Y.L.; Qian, H.; Yao, W.R. Synergistic antifungal mechanism of thymol and salicylic acid on Fusarium solani. LWT-Food Sci. Technol. 2021, 140, 110787. [CrossRef] 